\title{
The effect of varying the pre-tension and area of reinforcement on the ultimate bending strength of concrete beams*
}

\author{
by J. M. Prentis, M.Sc.(Eng.), Ph.D.
}
ERRATA: p. 146, Table 1 and p. 148, Figure 4. The symbol $n$ should read $n_{1}$.
p. 149, Figure 5. The strain scale should be doubled, i.e. it should read from zero to 0.016 , instead of from zero to 0.008 .

Contribution by Professor A. L. L. Baker, D.Sc., M.I.C.E., M.I.Struct.E.

In view of the small size of Dr Prentis's beams, and also the possible variation of ultimate concrete stress and distribution of stress, even under laboratory conditions, the differences between the theoretical and test results shown in Figure 4 of the paper are not unreasonable. My recommended values of the various factors included in the formula for ultimate bending strength (1) are safe limiting values. A value of $\alpha c^{\prime}=0.5 c_{u}$, when $c_{u}>4,000$ $\mathrm{lb} / \mathrm{in}^{2}$, has been suggested, and $0 \cdot 6 c_{u}$ when $c_{u}<4,000$ $\mathrm{lb} / \mathrm{in}^{2}$. The value of $c_{u}$ for the concrete may vary by $15 \%$ or more about the mean value. Dr Prentis must have used a fine concrete with a fairly high mortar content on account of the small beam section. A value of $\alpha c^{\prime}=$ $0.65 c_{u}$ is therefore quite reasonable. When $n_{1}=0.8$, the value of $M / b d^{2} c_{u}$ in Figure 4 is shown as 0.27 by theory and 0.34 by test. The former value is based on $\alpha c^{\prime}=$ $0.5 c_{u}$ which, if increased to $0.65 c_{u}$, gives $M / b d^{2} c_{u}=0.32$. It is, of course, also possible, as Dr Prentis suggests, that the value of $F^{\prime}$ is greater than 1 . The value 1 has been proposed as a safe maximum value, but with very good bond and a short, fine crack below the low neutral axis the value may be greater than 1 , but it is doubtful if it could be greater than 2. Dr Prentis's high values of 3.9 and 4.8 may, as he infers, be due to an overestimate of the depth of the neutral axis and an underestimate of the concrete compression strain at the section of failure.

Referring, for example, to beam A2 and Figure A, $e^{\prime}{ }_{c}=0.0042$ and $n_{1} d=1.94 \mathrm{in}$. A gauge length of $12 \mathrm{in}$. has been used on a $2 \frac{1}{2}$ in. deep beam. The average concrete strain, therefore, may be smaller than the local strain at the section of cracking and failure by as much as 0.002 . The position of the neutral axis is also derived from the average compression strain and assumed uniform curvature of the beam. The actual position of the neutral axis at the cracked section of failure may have been at a depth of only $1.6 \mathrm{in}$. The crack would tend to reduce the value of $n_{1}$ locally. The virtual tensile concrete

*Pages 143-150.

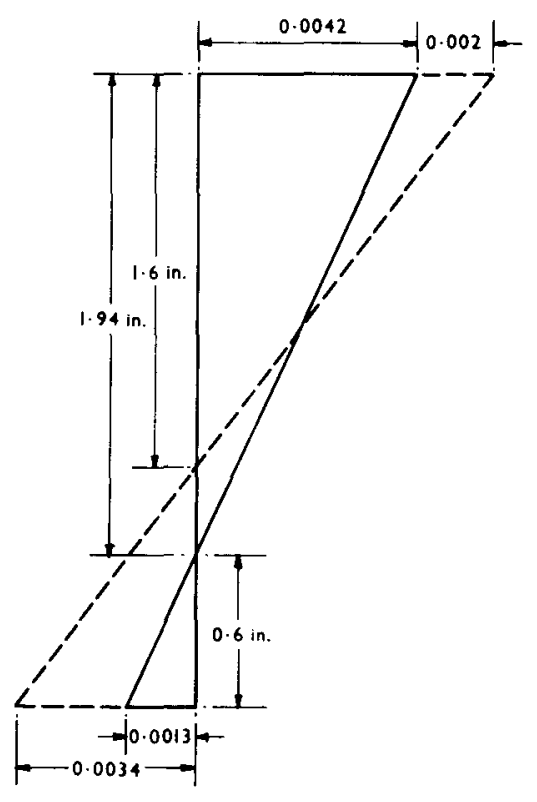

Figure A

strain would then be 0.0034 instead of 0.0013 . The steel strain at failure less the pre-strain is $e^{\prime}=0.005$ (derived from Figure 5 of the paper). The value of $F^{\prime}$ would then be $\frac{0.005}{0.0034}=1.47$, instead of 4.8 as given by Dr Prentis. Moreover, the value of $e^{\prime}{ }_{s}$ may have been overestimated slightly due to the actual lever arm value being greater than assumed. The value of $e_{s}^{\prime}$ could easily be reduced to 0.004 for that reason, making $F^{\prime}=1 \cdot 2$. Figure A shows that values of $F^{\prime}$ are very sensitive to small changes in the value of $n_{1}, e_{c}^{\prime}$ and $e^{\prime}{ }_{s}$ when $n_{1}$ is greater than 0.75 . Conversely, values of $M / b d^{2} c_{u}$ are not greatly increased by very large increases in the value of $F^{\prime}$ above 1 . It therefore appears satisfactory for safe design to limit the value of $F^{\prime}$ to 1 . Both Gray(1) and Leung ${ }^{(1)}$ found values of $F^{\prime}$ to be about 1 .

\section{REFERENCE}

(1) BAKER, A. L, L. Recent research at Imperial College on the design of reinforced concrete frameworks by ultimate load theory. Reinforced Concrete Review. Vol. 3, No. 6. 1954. pp. 313-353. 


\section{Contribution by A. J. Ashdown}

From a geometrical point of view, the device employed by the author for finding the position of the neutral axis is extremely elegant, but can be considerably in error when applied to concrete near the ultimate condition, for the following reason.

At a longitudinal compressive strain of about 0.001 the concrete starts bulking, and this increases rapidly with further pressure, a considerable vertical extension occurring between the neutral axis and the surface, so much so that just before final crushing, horizontal cracks open out.

Since all the beams failed by crushing within the gauge length, and the ends of the gauge were restrained from moving upward by the proximity of the loading plates, it follows that the centrally measured deflexion due to curvature would be reduced by the bulking movement, and hence would give too high a value for the radius of curvature, and an entirely erroneous value of $n_{1}$. It is possible also that the radius of curvature would be smaller over a shorter highly strained length.

Another possible cause for the large values of $n_{1}$ given may have been that the upward curvature due to the prestressing moment had been neglected, but whether this was allowed for or not, it would have been very small in these beams, owing to the small eccentricity.

In the case of beams without prestress, the following values are quoted in Table 1 of the paper:

A1: $n_{1}=0.71$ with $p=0.453 \%$;

$\mathrm{Cl}: n_{1}=0.52$ with $p=1.22 \%$.

As the concretes are of much the same strength, one should expect $n_{1}$ in beam A1 to be less than $n_{1}$ in beam Cl with a smaller percentage of steel. The large values of $n_{1}$ give very low average concrete stresses $\alpha c^{\prime}$ for these two beams, and the failing moment of $\mathrm{A} 1$ seems very low. Since both these beams failed in compression it may be interesting to compare $M / b d^{2} c_{\nu}$ values with the Whitney factor of $0.33 b^{2} C_{c}=M$; assuming $c_{u}=$ $1.25 C_{c}$, then we have $0.128 \times 1.25=0.16$ for beam $\mathrm{A} 1$, and $0.258 \times 1.25=0.312$ for beam $\mathrm{Cl}$, which seems to indicate that the concrete in beam $\mathrm{Al}$ must have been extremely poor compared with the cube strength, or it may have failed by bond slip, which is more likely.

By definition, and provided that the validity of the expression for the ultimate moment of resistance is assumed, the factor $F$ cannot be more than 1, and the high values found will reduce rapidly if $n_{1}$ is smaller and $e^{\prime} s$ is reduced in consequence of the greater lever arm.

In the writer's opinion, at the critical section of prestressed beams the stress condition is analogous to a column under eccentric loading, and pure bending assumed for the ultimate condition is incorrect, except for the case of steel yield failures where

$$
M_{u}=A_{t} t_{y} d\left(1-\gamma n_{1}\right) ;
$$

provided that $n_{1}$ is estimated correctly, this gives results in close agreement with experiment.
Contribution by K. Hajnal-Kónyi, Dr.Eng., M.I.C.E., M.I.Struct.E., M.Am.Soc.C.E., M.Cons.E.

On reading Dr Prentis's paper for the first time I had the impression that he had succeeded in proving the reliability of Professor Baker's theory. Indeed, both Tables 1 and 2 show a very substantial increase of the ultimate bending moment with increasing prestress and increasing percentage of reinforcement, and the plotted results in Figure 4 fit Professor Baker's curve reasonably well. If two series of tests have been carried out by two independent research workers and show such close agreement as may be seen from Tables 1 and 2 there seems to be no scope for any doubt. It is only necessary to do more tests to determine the variation of $F^{\prime}$ " dependent on the amount of pre-tension" so as to arrive at " a further equation to allow for variations of $F^{\prime \prime \prime}$ although this "will probably complicate the theory and make it more difficult to apply". It may therefore be expected that by doing more research the theory will be firmly established even if it will not be applicable for practical design.

However, on second reading, I began to have some doubts about Dr Prentis's interpretation of the test results and found a number of points very puzzling.

(1) How is it possible to have a value of $\alpha c^{\prime} / c_{u}=0.25$ in beam $\mathrm{Al}$ in concrete of $c_{u}=3,440 \mathrm{lb} / \mathrm{in}^{2}$ if Professor Baker suggests a "safe limiting value" of 0.6 ? (The italics are mine.)

(2) How is it possible that Prentis's beam C1 failed in compression at an ultimate bending moment of 6,640 lb. in. whilst Nisbet's beam $\mathrm{NCl}$ failed at an ultimate bending moment of only $5,800 \mathrm{lb}$. in. although the cube strength of the former was only $3,650 \mathrm{lb} / \mathrm{in}^{2}$ as against $5,800 \mathrm{lb} / \mathrm{in}^{2}$ of the latter?

(3) Figure 4 is described as "Comparison of experimental and theoretical results". One would expect, therefore, that the black circles in the lower half of the diagram represent the values $M_{u l t} b d^{2} c_{u}$ as ordinates plotted against the values $n_{1}$ in Table 1 as abscissae, whilst the hollow circles represent the corresponding values on the basis of Table 2, and values of $n$ measured by Nisbet but not included in his Table. Further examination reveals, however, that by plotting the values from Table 1 a very different picture would be obtained, e.g. the values given for beam Al in Table 1 are $M_{u l t} / b d^{2} c_{u}=0.128$ and $n_{1}=0.71$, whilst in Figure 4 the black circle corresponding to an ordinate of 0.128 is plotted against an abscissa of 0.32, i.e. less than half the experimental value!

The explanation of this amazing discrepancy is given by the author himself on page 147: "Using Professor Baker's constants the position of the neutral axis can be obtained for each of the beams tested by intersection of the appropriate $c_{u} / p_{s}$ and $t_{o}$ curves. The experimental values for $M / b d^{2} c_{u}$ have been plotted against these calculated values of $n_{1}$ in the lower half of Figure 4. Altogether sixteen results are plotted, the author's series, 
with beams $\mathrm{A} 3$ and $\mathrm{B} 1$ omitted, and the nine results obtained by Mr Nisbet".

This is an unusual, and for me entirely new, method of comparing test results with theoretical values. Whilst the curve in the lower half of Figure 4 represents Professor Baker's theory, the circles represent the values which are half experimental, half theoretical. In other words, the values $M_{u l t} / b d^{2} c_{u}$ obtained from tests are plotted against values of $n$ as they should have been on the basis of the curves in the upper half of Figure 4, and not as they were in fact obtained from the tests! Had the circles in the lower half of Figure 4 been plotted as purported by the caption, the black circle for A1 would be far on the wrong side of the curve and would have disturbed the apparent harmony between the test results and Professor Baker's theory. What can be the reason for the great deviation of the true experimental value of A1 (i.e. plotted against the measured value of $n$ ) from Professor Baker's curve?

(4) We were told in the past that Professor Baker's factor $F^{\prime}$ " is generally found to be between 0.85 and 1 when bonded bars are used as reinforcement".(1) Professor Baker anticipated the possibility of an increase to "say 1.5 , but not to 2 or 3 ". In his contribution to the discussion"11 Dr Prentis expressed the opinion " that many more tests need to be made before an $F$ factor greater than 1.0 could be used with confidence in design ". Now we are confronted in Table 1 with values of $F^{\prime}$ varying between 1.4 and 4.8 !

(5) How is it possible to have compression failure at $M_{u l t} / b d^{2} c_{u}=0.083$ with $p=0.453 \%$ in concrete of $c_{u}=5,200 \mathrm{lb} / \mathrm{in}^{2}$ (beam NA1) whilst I obtained failure in tension (fracture of the wires) at $M_{u l t} / b d^{2} c_{p}=0 \cdot 136^{(1)}$, equivalent to $M_{u l t} / b d^{2} c_{u}=0.091$, with $p=0.180 \%$ in concrete of $c_{u}=5,400 \mathrm{lb} / \mathrm{in}^{2}$ and wires of similar size but of greater extensibility? A comparison of Dr Prentis's Figure 5 with my Figure 10 will show that the strain in his wires at a stress of 125 tons/in ${ }^{2}$ was only 0.007 whilst at this strain the stress in my wires was only $82 \mathrm{ton} / \mathrm{in}^{2}$. Would one not expect an increase of $M_{u l t} / b d^{2} c_{u}$ by more than doubling the percentage and by using a wire in which the stress is so much higher at comparable strains?

Dr Prentis's stress-strain diagram (corrected as indicated in the Errata) is not very different from mine, although the stresses at comparable strains are still slightly higher. Even if the wires had been of the same quality, however, the reduction of $M_{u l t} / b d^{2} c_{\mu}$ with an increase of $p$ from 0.18 to 0.453 would be puzzling.

The key to the solution of these puzzles is beam B1 which, according to Dr Prentis, " unfortunately failed in shear". This statement is rather surprising and calls for a calculation of the maximum shear stress. Using the usual formulae and notation $a=0.865 \times 2.5=2.16$ in.

$$
S=\frac{6,880}{15}=459 \mathrm{lb} \text { and } s=\frac{459}{2.16 \times 1.5}=141.5 \mathrm{lb} / \mathrm{in}^{2}
$$

A shear failure of concrete of cube strength $4,930 \mathrm{lb} / \mathrm{in}^{2}$ at a shear stress of $141.5 \mathrm{lb} / \mathrm{in}^{2}$ is not probable $\left(s / c_{u}=\right.$ 0.0287).

Let us now consider the bond stresses at failure in the three beams in Table 1 with untensioned wires (see Table I).

\section{TABLE I}

\begin{tabular}{|c|c|c|c|}
\hline Beam mark & Al & B1 & $\mathrm{C} 1$ \\
\hline$M_{\text {ult }} \quad$ (lb.in.) & 4,120 & $>6,880$ & 6,640 \\
\hline (in.) & $\begin{array}{c}0.898 \times 2.5 \\
=2.24\end{array}$ & $\begin{array}{c}0.865 \times 2.5 \\
=2.16\end{array}$ & $\begin{array}{c}0.850 \times 2.5 \\
=2.12\end{array}$ \\
\hline (in.) & $\begin{array}{c}2 \pi \times 0.105 \\
=0.66\end{array}$ & $\begin{array}{c}4 \pi \times 0.105 \\
\quad=1.32\end{array}$ & $1 \cdot 32$ \\
\hline$S=\frac{M_{u l t}}{15}(\mathrm{lb})$ & 275 & $>459$ & 443 \\
\hline$\left(\mathrm{lb} / \mathrm{in}^{2}\right)$ & 186 & $>161$ & 159 \\
\hline
\end{tabular}

The picture would not be substantially different if the bond stress were related to the overall length of the wires, i.e. to the distance between the end of a beam and the loading point (not given in the paper).

The above figures show that in the three beams in question the stress $B_{2}$ at failure varied only between 159 and $186 \mathrm{lb} / \mathrm{in}^{2}$ and suggest that all three beams failed by bond slip. A failure by bond slip can often be discovered only if the end of the reinforcement is controlled by dial gauges, which was apparently not done in the present series. It is indeed difficult to avoid this type of failure with untensioned wires in such short beams as used in the present series of tests. A special surface treatment is necessary to improve the bond. In my tests on much longer beams I had failure in two beams by bond slip at a stress of $B_{2}=100 \mathrm{lb} / \mathrm{in}^{2}$. These were not included in my earlier paper(1) since they were irrelevant for the purpose of my tests. The only conclusion which could be drawn was that the bond was insufficient to allow the development of the full strength of the wires. Indeed, Dr Prentis has been fortunate to reach such high bond stresses as the above values. This was probably due to the very short duration of the test.

In this connexion I have to refer to a paper by Janney ${ }^{(2)}$ and to my contribution to the discussion. Janney's beam with untensioned clean wires failed at an average bond stress of $97 \mathrm{lb} / \mathrm{in}^{2}$. In the same type of beam with rusted wires the reinforcement was fractured at an average bond stress of $364 \mathrm{lb} / \mathrm{in}^{2}$. Had Dr Prentis and Mr Nisbet used rusted wires, no doubt Tables 1 and 2 would have presented an entirely different picture. It should be understood, of course, that the calculated bond stresses are average values and that in fact much higher peak values occur. As the load increases, this peak-which starts from the first crack-moves towards the end, until the bond is gradually destroyed over the 


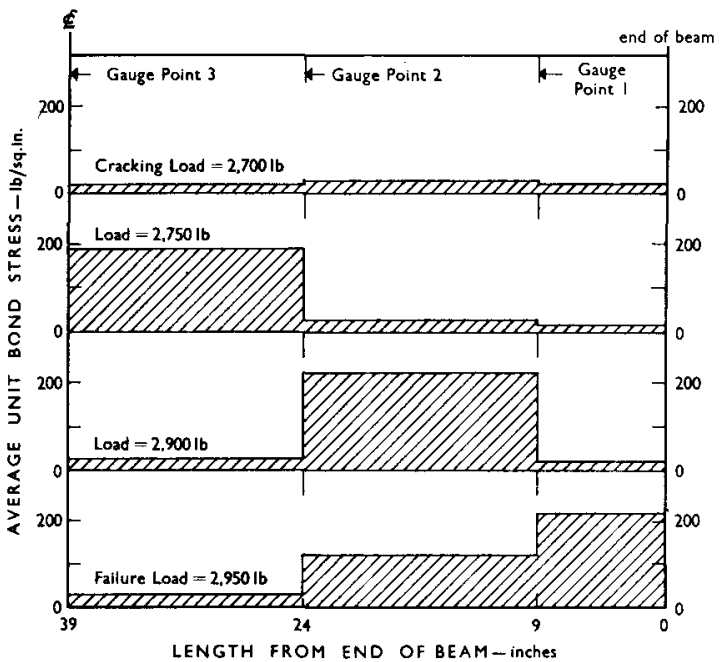

Figure B: Janney's beam Ic (no prestress). ${ }^{(2)}$

full length. This process is well illustrated by Janney's diagram, reproduced here as Figure B.

Now to the beams with pre-tensioning. Pre-tensioned wires can be held at higher local bond stresses than untensioned wires because of the wedging effect at the ends where the diameter of the wires increases at release. When such a beam is loaded there is very little change in the bond stresses until the first crack occurs. From then onwards the beam behaves like a non-pre-tensioned beam for any additional load and the wave of bond stresses moves from the crack towards the end until it reaches the range in which bond stresses are built up by pre-tensioning. Failure occurs when the sum of the two bond stresses reaches a critical value. It is interesting to analyse Dr Prentis's beams with medium prestress from this point of view (see Table II).

It may be seen that $\Delta B_{2}$ in beams $A 2$ and $B 2$ is slightly less than $B_{2}$ in $A 1$ and $B 1$, as was to be expected from Janney's tests (see Figure $C$ ) and the preceding explanation. These beams must also have failed by bond slip.* On the other hand, in the case of beam C2 there was a true compression failure as indicated both by the low value of $\Delta B_{2}$ above and by the high value of $M_{u l t} / b d^{2} c_{u}=$ 0.342 in Table 1. Beam A3 does not lend itself to analysis. Beam B3 also failed in true compression and so did beam $\mathrm{C} 3$ when the first crack occurred.

The behaviour of Dr Prentis's beams which failed by

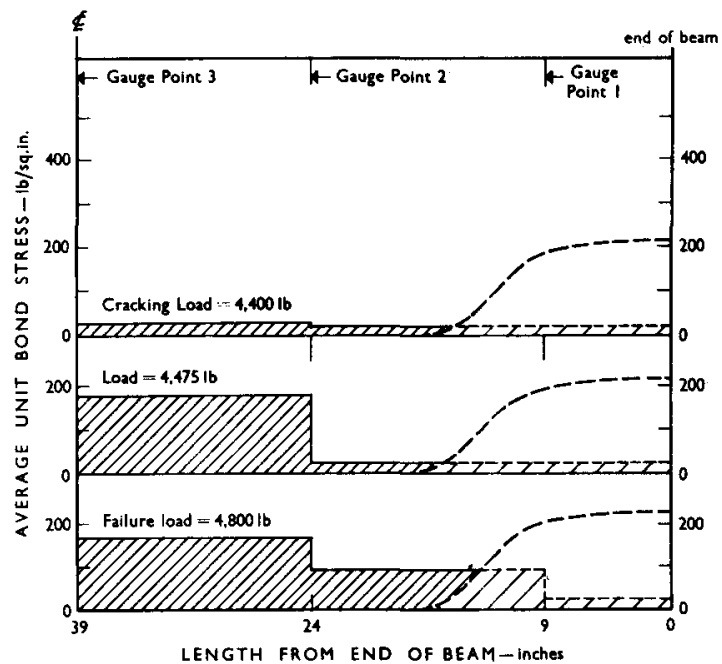

Figure C: Janney's beam $2 c\left(\right.$ prestress $=60,000 l b /$ in $\left.^{2}\right) .^{(2)}$

TABLE II

\begin{tabular}{|c|c|c|c|c|}
\hline \multicolumn{2}{|l|}{ Beam mark } & \multirow{2}{*}{$\frac{\mathrm{A} 2}{7,400}$} & \multirow{2}{*}{$\begin{array}{c}\text { B2 } \\
11,750\end{array}$} & \multirow{2}{*}{$\frac{C 2}{8,740}$} \\
\hline $\begin{array}{l}\text { Ultimate bending } \\
\text { moment }\end{array}$ & (lb.in.) & & & \\
\hline Cracking moment & (lb.in.) & 3,960 & 5,650 & 6,260 \\
\hline Difference $\Delta M$ & (lb.in.) & 3,440 & 6,100 & 2,480 \\
\hline$\Delta S=\frac{\Delta M}{15}$ & (lb) & 230 & 407 & 165 \\
\hline$\Delta B_{2}$ & $\left(\mathrm{lb} / \mathrm{in}^{2}\right)$ & 166 & 143 & 60 \\
\hline
\end{tabular}

bond slip is very well summed up in Janney's paper: "High bond stresses develop only after cracking has occurred, and consequently, if loss of bond is the cause of beam failure, a prestressed beam will carry a greater ultimate load than an unprestressed beam reinforced with the same steel. However, test results also indicate that the length of steel available for flexural bond stresses after beam cracking is reduced by the greater part of the prestress anchorage length (the length of the steel at the ends of a beam required to transfer the pre-tension force to the beam)".

Table 2 does not contain sufficient data for a similar

\footnotetext{
*Dr Prentis has drawn my attention to the fact that he had left the anchorages on the beams during his tests. I was not aware of this when 1 analysed his test results and have to add the following.

The presence of end-anchorages has, of course, prevented the slipping of the wires at the ends of the beams and deprived Dr Prentis of the possibility of observing failure in bond. However, the end-anchorages had no influence whatsoever on the bond and could not prevent bond failure. What they achieved was that after the bond had failed, the beams, originally provided with bonded wires, were transformed into beams failure. What they achieved was that after the bond had failed, the beams, originally provided with bonded wires, were transformed into beams
with end-anchored unbonded wires. Thus, the term "bond slip "applies to the whole length of the beams with the exception of the ends. It is not possible to say whether failure of the beams occurred immediately when the bond was destroyed, or whether a further increase of the load took place until the beams failed owing to the excessive elongation of the end-anchored wires which were no longer bonded.
} 
analysis but it is clear from the values $M_{u l t} / b d^{2} c_{u}$ in comparison with Table 1 that all beams must have failed by bond slip with the possible exception of $\mathrm{C} 2$ and $\mathrm{C} 3$ which might have failed in compression although even the highest value of $M_{u l t} / b d^{2} c_{u}$ in beam NC3, i.e. $0 \cdot 315$, falls short of the values obtained in beams B3, C2 and C3. In this connexion I was rather surprised by the following remark made by Dr Prentis on p. 148: "Thus, with increased pre-tension, the bond stresses which need to be developed are less, so that there is less tendency to slip and $F$ increases." (My italics.)

This statement implies premature failure by bond slip with insufficient pre-tension. This is indeed what happened in the majority of the beams under discussion, but if Dr Prentis was aware of this why did he speak of shear failure and failure in bending? The purpose of his research was not to investigate failure by bond slip (which was Janney's purpose) but to establish the influence of increased percentage and increased prestress when the mode of failure is not changed by the prestress from bond slip into compression. In the whole discussion on my earlier paper ${ }^{(1)}$ it has been assumed that failure would be either in tension or in compression. If beams which failed by bond slip are included in the comparison the whole issue is confused.

In view of the foregoing the conclusions made by Dr Prentis have to be modified. It is obvious that Professor Baker's theory of failure by concrete crushing cannot be applied to cases of failure by bond slip.

The effect of increased percentages and increased pretensioning can only be ascertained from beams which fail either in tension or in compression. Thus, the only beams on which relevant conclusions can be based are B3, C2 and C3.

These tests have proved that with high percentages of reinforcement and high prestress the value of $M_{u l t} / b d^{2} c_{u}$ can be as high as 0.372 . It is regrettable that no prism strengths and cylinder strengths are available so that the results cannot be expressed in terms of $c_{p}$ or $c_{c}$. Although in general I suggest a ratio $c_{p} / c_{\mu}$ of 0.6 to 0.75 if no information is available, this ratio may in fact be much higher. In tests recently carried out at the laboratory of the Cement and Concrete Association in collaboration with $\mathrm{Mr} \mathrm{H}$. E. Lewis ${ }^{(3)}$, the ratio $c_{c} / c_{u}$ varied in a large number of tests between 0.80 and 0.92 . With these limits the above ratio of $M_{u l t} / b d^{2} c_{u}$ would be equivalent to a ratio $M_{u t t} / b d^{2} c_{c}$ of 0.404 to 0.465 . This is 21 to $40 \%$ higher than Whitney's limit and seen is to represent the maximum that may be expected in over-reinforced overprestressed beams.

Whilst it is very interesting from the theoretical point of view to see how far one can go with $M_{u l l} b d /{ }^{2} c_{u}$, the mode of failure of beam $\mathrm{C} 3$ is a warning against the use of such beams in practice. Even a beam like $\mathrm{C} 2$, with a ratio of cracking moment to ultimate bending moment of $6,260 / 8,740=0 \cdot 715$ is dangerous and must not be used.

In the closure of the discussion on my paper ${ }^{(1)}$ I stated: "In the range where even a high degree of prestress does not cause fracture of the steel, an increased prestress is likely to increase the maximum bending moment if the percentage exceeds a certain limit, but I expect that the curves showing the effect of increased prestress do not diverge so much as in Mr Prentis's Figure 5, and flatten out."

The first part of this statement has been confirmed by Dr Prentis's tests; the second has yet to be proved or contradicted by tests in which no bond slip occurs.

Hitherto we were made to believe that high values of $F$ (greater than 1) were an indication of good bond. Now Dr Prentis has shown that $F$ " increases with pre-tension " and values as high as $4 \cdot 8$ can be obtained even if failure is caused by bond slip.

\section{REFERENCES}

(1) HAJNAL-KÓNYI, K. Tests on concrete beams reinforced with 12 gauge wires of an ultimate strength of 120 tons per sq.in. Magazine of Concrete Research. Vol. 3, No. 9. March 1952. pp. 113-121. Contribution to discussion by A. L. L. Baker. pp. 121-127. Discussion Vol. 4, No. 12. April 1953. pp. 127-142.

(2) JANNEY, J. R. Nature of bond in pre-tensioned prestressed concrete. Journal of the American Concrete Institute. Vol. 25, No. 9. May 1954. pp. 717-736. Discussion Vol. 26, No. 4. December 1954. pp. 736/1-736/11.

(3) HAJNAL-KÓNYI, K. and LEWIS, H. E. Moment redistribution in continuous beams reinforced with plain and deformed bars. Symposium on the Strength of Concrete Structures, London, May 1956. Session B, Paper No. 4. pp. 36.

\section{Contribution by Stephen Revesz, M.Sc., D.I.C., A.M.I.C.E., A.M.I.Struct.E}

Dr Prentis states that the percentage reinforcement in his test beams was sufficient to preclude failure by steel rupture. The real point of interest is: what is this percentage? The writer carried out tests on pre-tensioned beams of $14 \mathrm{ft} 0 \mathrm{in}$. span with varying degrees of prestress ${ }^{(1)}$, and the results of the tests are plotted in Figure D. The ordinate of the graph is $M / b d^{2} c_{u}$ and the abscissa $p t_{u} / c_{u}$, where the suffix $u$ denotes ultimate strength. Of the ten results plotted, nine were by fracture of the steel and one (untensioned wires) by concrete crushing due to excessive elongation of the steel. The approximate ratio of the prestress to the ultimate strength of the steel is marked adjacent to the plotted points.

The test results reported by Dr Prentis are also plotted on the same diagram.

Even allowing for the different range of values of $p t_{u} / c_{u}$, the ultimate loads reached by Prentis's test beams are those to be expected with end anchored, grouted rather than pre-tensioned beams.

Examination of the flexural bond stresses shows* that

\footnotetext{
*See Dr Hajnal-Kónyi's contribution.
} 


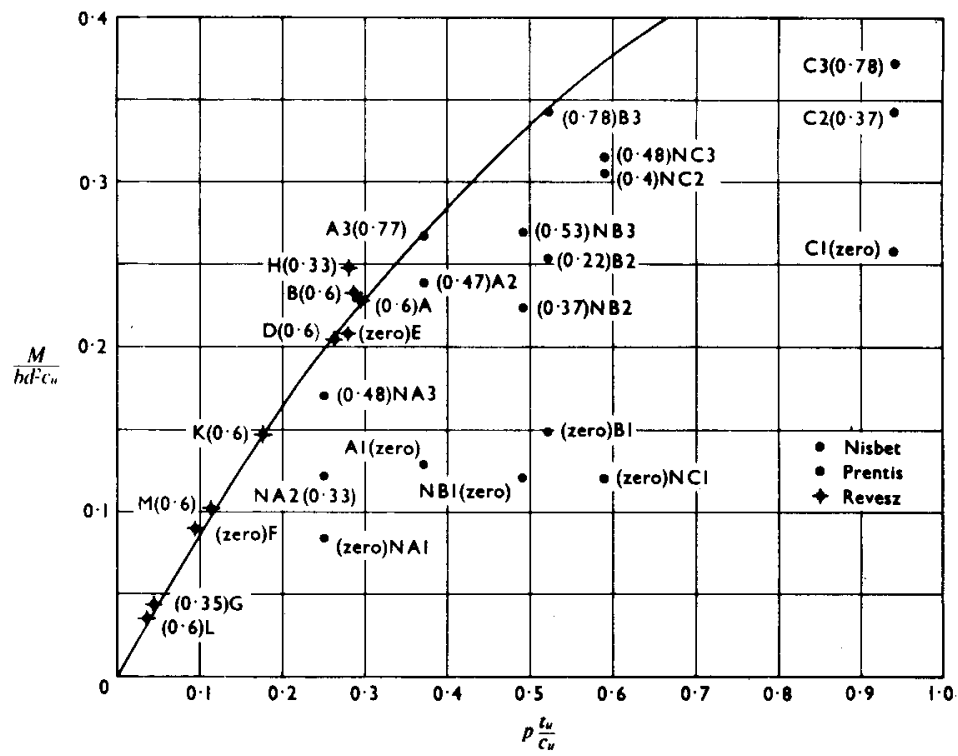

Figure $D$

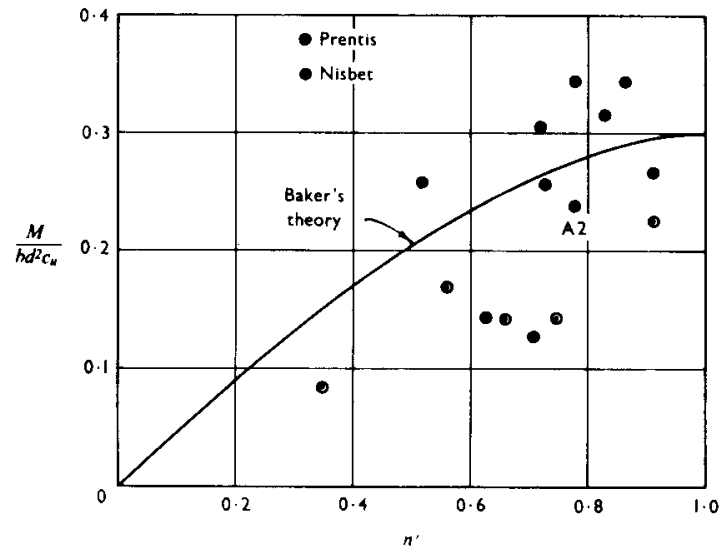

Figure E

the majority of the beams reported by Dr Prentis failed in bond, and the span of $3 \mathrm{ft} 9 \mathrm{in}$. was too short for the experiment. The conclusions drawn by Dr Prentis from these tests are therefore not valid.

Dr Prentis has kindly supplied the writer with further information about the tests, which is plotted in Figures $E$ and $F$. Both diagrams display a remarkably large scatter of values. The depths of the neutral axes (as measured) are so erratic that they are suspect, and therefore any derived coefficients of $F^{\prime}$ and $\alpha c^{\prime} / c_{u}$ are bound to be completely wrong. It must be emphasized that nothing is proved by Figure 4 of Dr Prentis's paper, since experimental values of $M / b d^{2} c_{u}$ are compared with

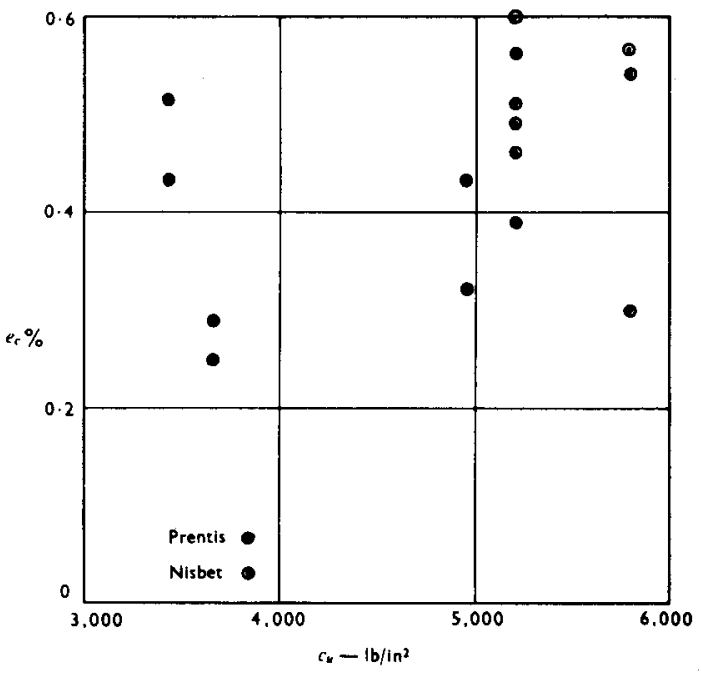

Figure $F$

theoretical values of $n_{1}$ : it is difficult to see how the diagram could prove or disprove Professor Baker's plastic theory.

Figure $\mathrm{G}$ illustrates the formation of cracks in a beam near ultimate load. It seems obvious that where no crack has occurred, the tensile strain in the concrete at the level of the steel must be very small. Thus the measured depth of the neutral axis, based on the curvature of the top fibre, is merely an average value, whereas the point of 


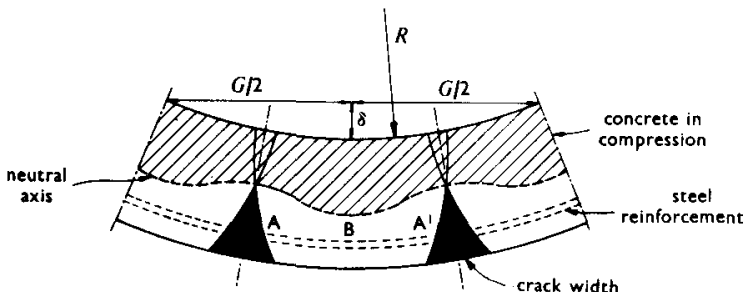

Figure $G$

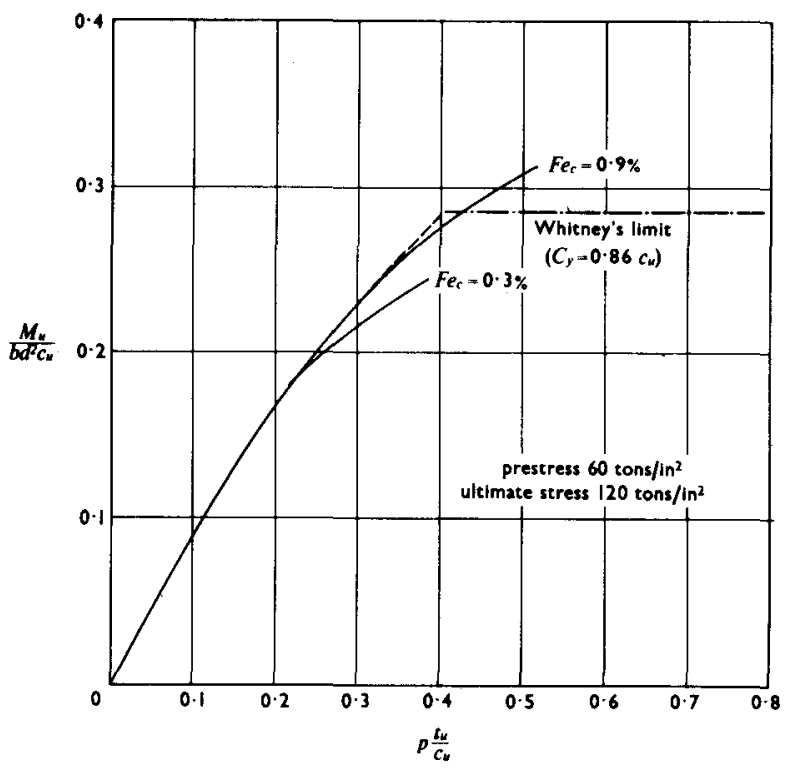

Figure $H$

real interest is the condition directly over a crack. It is also possible that the compressive strain over a crack is greater than in the adjacent concrete due to plastic deformation particularly in that zone. Hence the coefficients of $\alpha c^{\prime} / c_{u}$ derived from normal beam tests are questionable, and may be influenced by the time taken for the tests.

Tests carried out on specially designed concrete sections ${ }^{(2)}$ yielded the following values based on cylinder tests:

Ultimate concrete cylinder

$\begin{array}{lccc}\text { strength }\left(\mathrm{lb} / \mathrm{in}^{2}\right) & 4,000 & 6,000 & 8,000 \\ k_{1} k_{3}=\alpha c^{\prime} / c_{u} & 0.74 & 0.65 & 0.6 \\ k_{2}=\gamma & 0.45 & 0.42 & 0.4 \\ e_{c}(\%) & 0.34 & 0.31 & 0.28\end{array}$

It would be desirable to obtain comparable values on concrete made from materials available in this country, and related to the cube strength. The relationship between cylinder, prism and cube strength found by different observers is so inconsistent that it is unreliable to take the American results as they stand. However, a set of coefficients must be established soon to avoid unnecessary guessing.

In Professor Baker's theory, the elongation of the steel is related to $F^{\prime} e^{\prime} c_{c}$ and $\left(1-n_{1}\right) / n_{1}$, where $n_{1}$ is a function of $\alpha c^{\prime} / c_{u}$. The elongation of the steel only becomes important in pre-tensioned beams at large values of $p t_{u} / c_{u}$. This is illustrated in Figure $\mathrm{H}$. The curves are based on a steel of 120 tons $/$ in $^{2}$ guaranteed ultimate strength (at $1.2 \%$ strain). The assumed prestress after losses is taken as 60 tons $/$ in $^{2}$. For the upper part of the curve, $\alpha c^{\prime} / c_{u}$ was taken from Figure 5 of an earlier paper by the writer(1) and $F^{\prime} e^{\prime}{ }_{c}$ values of $0.3 \%$ and $0.9 \%$ have been considered. Thus $F^{\prime} e^{\prime}{ }_{c}=0.3 \%$ may represent $F^{\prime}=1.5$ and $e^{\prime}{ }_{c}=0.2 \%$

$F^{\prime} e^{\prime}{ }_{c}=0.9 \%$ may represent $F^{\prime}=2$ and $e^{\prime}{ }_{c}=0.45 \%$

Further research is still required on the behaviour of pre-tensioned beams, where $t_{p}=\frac{1}{2} t_{u}$, in the range examined above. This would then complete the essential data required by designers.

The fact to remember is that the investigation of pretensioned beams with only untensioned high-tensile wires is largely an academic pursuit, and that the upper limit of $p t_{u} / c_{u}$ is governed by practical considerations of economy, allowable prestress in the concrete, and space in the section. It is therefore important to appreciate that, within practical limits, pre-tensioned beams may be designed on the basis of a tensile failure.

Regarding the terminology "compression failure" in Dr Prentis's notation, this is referred to by Professor Baker as "failure by concrete crushing", which is a true description of the visual event at the collapse of a concrete beam. However, the latter term gives no indication as to the primary cause of failure, and this may be (i) tensile, (ii) bond slip, (iii) excessive elongation (not strain) of the steel, (iv) "primary compression" (in normal reinforced concrete beams).

The correct interpretation of 'concrete crushing' is therefore a difficulty which must confront the engineer using the plastic theory. Evidence of concrete crushing is not proof of compression failure. Compression failure is failure due to insufficient concrete strength in the compression zone and is not primarily due to insufflcient bond. In pre-tensioned beams the behaviour follows (up to a practical limit) a comparatively simple law: the theory with guessed coefficients is difficult to apply to pretensioned beams, not because the concrete is too plastic, but because the theory becomes too elastic !

\section{REFERENCES}

(1) REVESz, S. Factors governing the ultimate bending moment of normal reinforced and prestressed beams, with reference to a proposed plastic theory. Magazine of Concrete Research. Vol. 5, No. 13. August 1953. pp. 11-26.

(2) HOGNESTAD, E., haNSON, N. W. and MCHENRY, D. Concrete stress distribution in ultimate strength design. Journal of the American Concrete Institute. Vol. 27, No. 4. December 1955. pp. 455-479. 


\section{Reply by the author}

In my paper I was careful to emphasize that the strain readings and quantities derived therefrom must be regarded as qualitative only and that high accuracy should not be attributed to them. It was realized from the first that this would be; I was not unduly concerned because my prime object was to determine ultimate bending moments. The strain gauge enabled me to measure accurately the pre-tension in the steel and in doing so fulfilled one of its purposes, for it is only after cracking that local strains differ appreciably from the average. I confess that the ultimate strain readings turned out to be even more approximate than had been expected; consequently I was careful to draw only tentative conclusions from them. It did not seem necessary to publish Mr Nisbet's strain results for they tell much the same story as my own.*

The lack of accuracy arises solely because of the use of too long a gauge length in relation to the size of the beams. At failure the length of the crushed zone was generally two to three inches compared with the gauge length of twelve inches. The average strain over the latter is clearly not closely related to local values of the former. In this connexion I cannot agree with $\mathrm{Mr}$ Ashdown regarding the "bulking" of the concrete. This phenomenon causes a relative movement between the neutral axis and the compression surface which could not be inhibited by the loading plates in the way which Mr Ashdown suggests. If crushing were to occur immediately under one of the gauge supports or under the micrometer point results would be invalidated, but once the concrete starts to disintegrate strain readings have little significance, whatever the method used to record them.

Although I felt detailed analysis of the strain results to be of little value I thought it reasonable to draw one or two general conclusions. One of these was that $F^{\prime}$ can be appreciably greater than $1 \cdot 0$. I am confident that further tests will substantiate this and suggest specific values. For the time being there are not sufficient data to warrant any modification of the opinion I expressed, which Dr Hajnal-Konyi has quoted, " that many more tests need to be made before an $F^{\prime}$ factor greater than 1.0 could be used with confidence in design ".

Professor Baker demonstrates that the true $F^{\prime}$ factors could be much less than the values which I have quoted. I agree, but $F^{\prime}$ and $e_{c}^{\prime}$ are always associated as a product in the theory. To reduce $F^{\prime}$ to his safe limit of 1.0 Professor Baker bases his calculation on $e_{c}^{\prime}=0.006$, for which he recommends a safe limit of 0.002 . This is simply robbing Peter to pay Paul.

It is not correct to say that $M / b d^{2} c_{u}$ is insensitive to large changes in $F^{\prime} e_{c}^{\prime}$ (see Figure 6 in the paper); if it were, Professor Baker's theory could easily be simplified in a way that does not yet seem possible.
Mr Ashdown says that $F^{\prime}$ must, by definition, be less than 1.0. I do not know what definition he has in mind; Professor Baker's definition certainly allows $F^{\prime}$ to be greater than $1 \cdot 0$. It is true that the $n_{1}$ values for beams $\mathrm{Al}$ and $\mathrm{Cl}$ are contradictory. In view of my opening remarks I do not think that anything can be deduced from this. Comparison of the ultimate moment for beam A1 with Whitney's $0.33 b d^{2} C_{c}$ confuses the issue. My concern is with Professor Baker's theory which predicts an ultimate moment of $0.14 b d^{2} c_{u}$ compared with the $0 \cdot 13 b d^{2} c_{u}$ realized in the test, though I agree that there may have been some bond slip in this case.

I do not understand Mr Ashdown's concluding paragraph. As far as the concrete is concerned the stress distribution is that brought about by an eccentric force but, as a unit, the member is certainly subjected to a pure bending moment over the centre portion of its length.

Before commenting on the contributions of Dr HajnalKónyi and Mr Revesz it will be convenient to state the equations of Professor Baker's theory. In the nomenclature of my paper these are

$$
\begin{aligned}
& n_{1}=T / \alpha c^{\prime} b d \ldots \ldots \ldots \ldots \ldots \ldots \ldots \ldots \\
& \text { or } n_{1}=t_{u} p_{s} / 100\left(\alpha c^{\prime}\right) \text {. } \\
& M / b d^{2} c_{u}=\left(\alpha c^{\prime} / c_{u}\right) n_{1}\left(1-\gamma n_{1}\right) \ldots \ldots \ldots \ldots \ldots \ldots \\
& n_{1}=\left(1+e^{\prime} s / F^{\prime} e_{c}^{\prime}\right)^{-1} \text {. }
\end{aligned}
$$

Dr Hajnal-Kónyi attacks me on two main scores: first, my presentation of the test results, as in Figure 4; secondly, my interpretation of the results.

In making the tests I had one object. This was to compare the ultimate bending moments of a number of beams with the theoretical moments according to Professor Baker's theory. Had I decided not to measure strains I should still have been able to make this comparison which can be presented in an infinity of ways. The most common method is to draw up a table with two columns, one headed "theoretical $M / b d^{2} c_{u}$ ", the other "experimental $M / b d^{2} c_{u}$ ". Preferring a graphical presentation I could have plotted the two columns to any base considered suitable. But it is essential to use the same base for both the theoretical and experimental moments.

Dr Hajnal-Kónyi claims that the experimental moments should be plotted to a base of experimental $n_{1}$, as in Mr Revesz's Figure E. Suppose that one of my beams had given the two experimental results $M / b d^{2} c_{u}=0 \cdot 2$, $n_{1}=0.5$. These two co-ordinates give a point right on the theoretical curve. It would be concluded that there was perfect agreement between theory and experiment quite irrespective of the fact that the experimental moment might be a half, say, or even double the theoretical moment. Let us consider an actual example. Beam A2 (which I have marked in) is shown with its 
point plotted below the theoretical curve in Figure E, implying that the experimental moment was less than the theoretical. The opposite was true. Figure E is useless because the experimental values of $n_{1}$ are inaccurate. Even if the strains had been measured precisely, Figure E would still serve little purpose; it would simply be an experimental verification of equation (2), whereas in Professor Baker's theory equations (2), (3) and (4) must all be considered.

Let us now turn to the interpretation of the test results. I ascribed the inconsistencies between the various results, and between the results and theory, to variations in the bond conditions. This led to the conclusion, quoted by Dr Hajnal-Konyi, that " with increased pre-tension, the bond stresses which need to be developed are less, so there is less tendency to slip and $F^{\prime}$ increases". Dr Hajnal-Kónyi misunderstands me when he says that this statement implies failure by bond slip with insufficient pre-tension. No such implication is intended for I was referring only to those local effects which bring about high values of $F^{\prime}$.

I have taken the liberty of adding reinforcement to Mr Revesz's Figure G, and the letters A, $A^{\prime}$ and B. At point $A$ the steel force has a certain value (at the ultimate moment this force is $A_{s} t_{u}$ ). Unless the bond between $A$ and $B$ is destroyed the steel force at $B$ is less than that at $A$ and $A^{\prime}$. The effective strain in the steel is that corresponding to the increase in steel stress from the prestress value to that at the load being considered. The effective concrete strain is equal to the average steel strain. The effective steel strain divided by the effective concrete strain gives $F^{\prime}$ which must be greater than 1.0 . As the bending moment is increased the bond stresses along $\mathrm{AA}^{\prime}$ increase, so there is increased tendency to slip. There must be some slip the instant the crack forms, otherwise the steel therein would have to appear from nowhere. As the crack widens the slip zones at $\mathbf{A}$ and $\mathbf{A}^{\prime}$ spread towards $B$, lowering the value of $F^{\prime}$. When the slip zones meet at $B$ the steel stress is constant from $A$ to $\mathrm{A}^{\prime}$ and $F^{\prime}=1 \cdot 0$. With increasing crack width $F^{\prime}$ decreases, from which it follows that anything which causes a reduction in crack width can be said to result in an increased value of $F^{\prime}$. For a fixed top fibre strain $\left(e^{\prime}{ }^{\prime}\right)$, the crack width at the steel level decreases as the depth of the neutral axis increases. It does this as the pre-tension is increased. Such reasoning led me to the conclusion that "with increased pre-tension ... $F^{\prime}$ increases".

Bond slip of the type just described must take place in any beam as it is loaded to failure. It would, however, be pointless to say in consequence that the primary cause of failure in all beams is bond slip.

I have felt it necessary to state the above in some detail because Dr Hajnal-Kónyi has misinterpreted me. I regret that my words were open to such misunderstanding. I agree that it would be wrong to talk of compression failure of beams which collapse due to a general bond slip of the type considered by Janney.
Dr Hajnal-Kónyi presents calculations which he claims prove that the majority of my beams failed by general bond slip.

In an earlier issue of the Magazine of Concrete Research ${ }^{(1)}$ Hognestad and Janney described a test which makes nonsense of these calculations. Two beams were made, identical in section, and each pre-tensioned with clean wires to $120,000 \mathrm{lb} / \mathrm{in}^{2}$. One beam was double the length of the other. On testing, with single point central loading, both beams cracked and failed at roughly the same moment, i.e. the longer failed at half the shear of the shorter. It therefore failed at half the average bond stress. Hognestad and Janney concluded that "flexural bond stresses at the crack are the best clue we have found so far in our search for a method of estimating the ultimate strength of pre-tensioned beams failing in bond".

They continue: "These bond stresses at the crack depend essentially on the difference in steel tension just before cracking and at the load considered". We can compute this difference for Janney's wires from Figure B. It can be seen that the bond stresses at the crack are about $190 \mathrm{lb} / \mathrm{in}^{2}$ averaged over $15 \mathrm{in}$. This gives rise to a steel force of $190 \times \pi \times 0.197 \times 15=1,760 \mathrm{lb}$ per wire, or a stress of $58,000 \mathrm{lb} / \mathrm{in}^{2}$. This stress is inversely proportional to the wire diameter. Thus, assuming the same surface condition for my wires as for Janney's the difference in steel tension needed to cause slip of 12 S.W.G. wire is $58,000 \times 0 \cdot 197 / 0 \cdot 105=109,000 \mathrm{lb} / \mathrm{in}^{2}$.

It is possible, therefore, that bond slip occurred in my beams in those cases where the steel stress increased by $109,000 \mathrm{lb} / \mathrm{in}^{2}$ or more. If we use the same lever arms as Dr Hajnal-Kónyi (his Table I) it is found that only in the case of beam $\mathrm{Al}$ is this value approached closely. For beam $A 1$ the increase in steel force is 4,120/2.24 = $1,840 \mathrm{lb}$; the increase in stress is $108,000 \mathrm{lb} / \mathrm{in}^{2}$.

One can only speculate about the relative surface conditions of Janney's wire and mine. If there was any surface corrosion of my wires it was not conspicuous. On the other hand if the wires were slightly rusty no particular notice would have been taken. Janney, however, was presumably particularly careful to choose unblemished wires as he was investigating bond conditions. It is unlikely, therefore, that my ultimate bond stresses were less than Janney's.

Even so I regret that steps were not taken to check experimentally whether or not bond failure took place. The end anchorages were left in position to prevent slip due to the pre-tension bond stresses, and it was assumed that the flexural bond stresses would not be high enough to cause failure. The only method of eliminating the possibility of flexural bond failure would have been to allow the wires to rust before use. Hognestad and Janney's test proves that it is no use simply lengthening the beams as suggested by Dr Hajnal-Kónyi and Mr Revesz.

If Janney's results are considered to be applicable to my beams it must be concluded that beam A1 failed in 


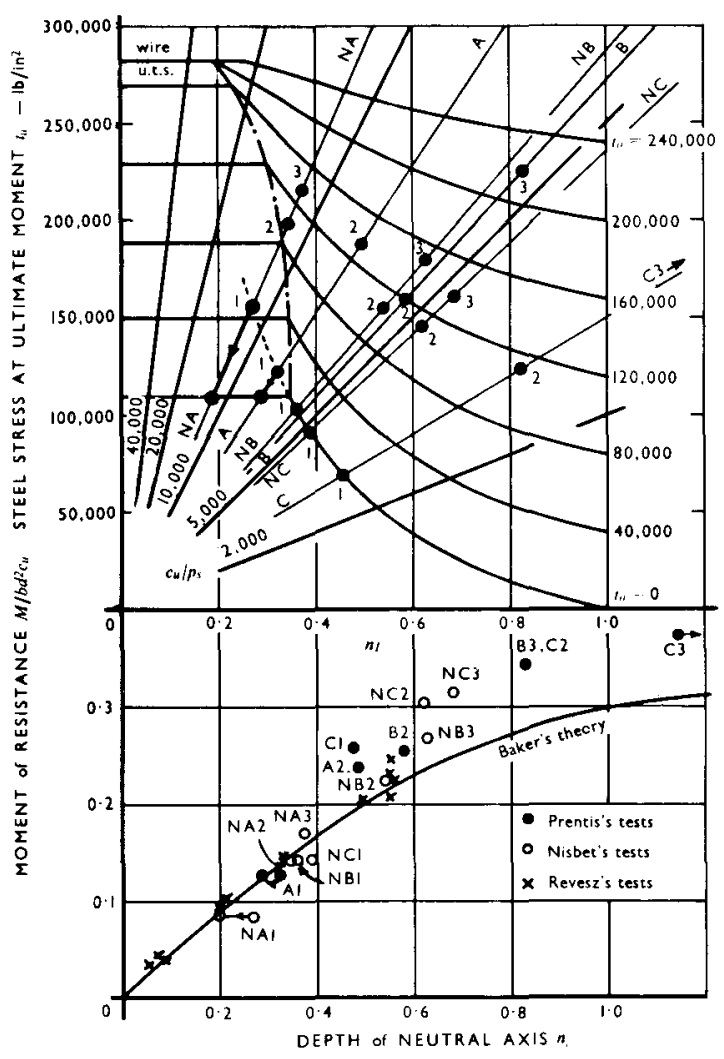

Figure $J$

bond and, as I shall show below, beam NA1. The evidence does not support Dr Hajnal-Kónyi's contention that a number of other beams also failed in bond.

Dr Hajnal-Kónyi values highly the use of quotation marks; one could wish that his regard for context was as great. The quotation from Janney "High bond stresses develop only after cracking has occurred ...." is misapplied. All Janney's bond failures occurred at loads only slightly in excess of the cracking load, a point to which Dr Hajnal-Kónyi makes specific reference in the discussion on Janney's paper. Table 1 in my paper shows that with the exception of beams C2 and C3, my beams failed at loads considerably in excess of the cracking load.

My Figure 4 can be amended to allow for bond failure as shown in Figure J. Bond slip occurs, in the case of smooth 0.105 in. diameter wire, when the steel stress exceeds the pre-tension by about $110,000 \mathrm{lb} / \mathrm{in}^{2}$. That is when $t_{u}=t_{o}+110,000$. This equation is shown in Figure $\mathrm{J}$ as a chain-dotted curve. To the left of this the $t_{o}$ lines run horizontally as shown. The diagram is used as before. Failure occurs by bond slip if the $c_{u} / p_{s}$ line and the amended $t_{o}$ curves intersect to the left of the chain-dotted curve. Figure $\mathrm{J}$ omits some of the $c_{u} / p_{s}$ lines of Figure 4 , but shows instead the intersection points for the beams tested. In the lower half of the diagram the original points have been labelled and some more have been added. It can be seen that on this basis beams A1 and NA1 appear to have failed in bond. For these two beams the intersection points needed to be shifted as shown. This leads to a replotting in the lower diagram which leads to agreement between the theoretical and experimental moments.

In Figure D Mr Revesz compares some of his results with mine. All but one of Mr Revesz's beams failed by steel fracture so that the amount of pre-tension, although it was varied, is of no consequence. This enables $\mathrm{Mr}$ Revesz to draw a neat curve through his results. This curve has, however, no relevance to my beams, since all but two failed in compression at loads which reflect the variations in pre-tension. It would be absurd, for example, to compare my C series beams with Mr Revesz's curve. The points for these beams appear in the top right-hand corner of the diagram. The curve is off the sheet here, but for $p t_{u} / c_{u}=0.94$ it appears to give $M / b d^{2} c_{u}=0.48$ ! Even so, Figure D does demonstrate that some of my moments are low compared with Mr Revesz's.

I hesitate to refer again to bond, but I think that the local bond stresses account for the discrepancies. I have shown that the increase in steel stress possible for smooth $12 \mathrm{~S}$. W.G. wires is limited to $110,000 \mathrm{lb} / \mathrm{in}^{2}$. This means that neither of Mr Revesz's untensioned beams should have failed by steel fracture because this entails an increase in steel stress of about $300,000 \mathrm{lb} / \mathrm{in}^{2}$. In one of these beams, however, the steel did fracture. It also fractured in beams $G$ and $H$ where the steel stress increased by about $200,000 \mathrm{lb} / \mathrm{in}^{2}$. This means that $\mathrm{Mr}$ Revesz's wires must have had much better bond properties than Janney's and mine. Presumably Mr Revesz's wires were rougher. Now if Mr Revesz's wires had a higher ultimate flexural bond strength than mine, it is likely that those local bond stresses, which lead to $F^{\prime}$ factors greater than $1 \cdot 0$, were also higher.

According to Professor Baker's theory most of Mr Revesz's beams should have failed in compression. The fact that they failed in tension again suggests that the value of $F^{\prime} e^{\prime}$ for these beams was very much higher than Professor Baker's 0.002 . I have pointed out in the paper that a high value of $F^{\prime} e^{\prime}{ }_{c}$ can lead to tensile failure where compression failure would be expected.

It is of interest to estimate $F^{\prime} e^{\prime}{ }_{c}$ for Mr Revesz's beams. Let us assume that, although beam E collapsed without the steel fracturing, the steel stress was close to the ultimate. Assume further that the stress-strain curve for the steel was the same as for my wires (in fact the ultimate strength of Mr Revesz's steel was $300,000 \mathrm{lb} / \mathrm{in}^{2}$ ). The value of $c_{u} / p_{s}$ for beam $E$ was 10,500 . Figure 6 in my paper shows that the $c_{u} / p_{s}=10,000$ line just cuts the $F^{\prime} e_{c}^{\prime}=0.016$ curve. None of the rest of $\mathrm{Mr}$ Revesz's beams has a value of $c_{u} / p_{s}$ less than 10,000 , and in no other case does the $c_{u} / p_{s}$ line cut the appropriate $t_{o}$ 
curve for $F^{\prime} e^{\prime}{ }_{c}=0.016$ (Figure 6 contains only one of these curves, i.e. $t_{o}=0$ ). Approximate values of $M / b d^{2} c_{u}$ for tension failures are obtained by projecting down from the intersections of the $c_{u} / p_{s}$ lines with the horizontal line $t_{u}=280,000 \mathrm{lb} / \mathrm{in}^{2}$, the ultimate strength of my wire.

I have added Mr Revesz's results to my Figure J. It can be seen that they lie close to the theoretical curve, as would be expected. It must be borne in mind that the theoretical values of $M / b d^{2} c_{u}$ for Mr Revesz's beams are on the basis of $F^{\prime} e^{\prime}{ }_{c}=0.016$, whilst mine are for $F^{\prime} e^{\prime}{ }_{c}$ $=0.002$.

Dr Hajnal-Kónyi's penultimate paragraph is interesting. Hitherto, Dr Hajnal-Kónyi has criticized Professor Baker's theory because it predicts increasing ultimate moment with increasing prestress and steel percentage for beams which do not fail by steel fracture. My tests resulted in values of $M / b d^{2} c_{u}$ in excess of those predicted by Professor Baker's theory. Yet Dr Hajnal-Kónyi claims that these results support the statement which he has quoted; he does not quote his prediction that Whitney's coefficient would apply to beams of this type.

Though I think that concern for the mode of failure is often overemphasized, I agree with Dr Hajnal-Kónyi that high values of $M / b d^{2} c_{u}$ are more of academic than practical interest. I agree also with Mr Revesz regarding the use of untensioned reinforcement. In making my tests I was seeking verification of the general predictions of Professor Baker's theory, in which design limitations are not considered.

Practical limits are set on the amount of pre-tension which can be employed, however. It is reasonable therefore to review Professor Baker's theory in the light of these limits to see if it can be simplified. Let us assume that the pre-tension lies between say 100,000 and 160,000 $\mathrm{lb} / \mathrm{in}^{2}$. Let it be assumed that under working load the stress distribution approximates to that shown in Figure $\mathrm{K}$. If we ignore the tensile stress in the concrete below the steel we obtain, for a rectangular beam, the relationship $t_{o}=50 c_{o} / p_{s}$. Suppose that $c_{o}=c_{u} / 3$, then $t_{o}=$ $16.6 c_{u} / p_{s}$. This equation, together with the lower limit of

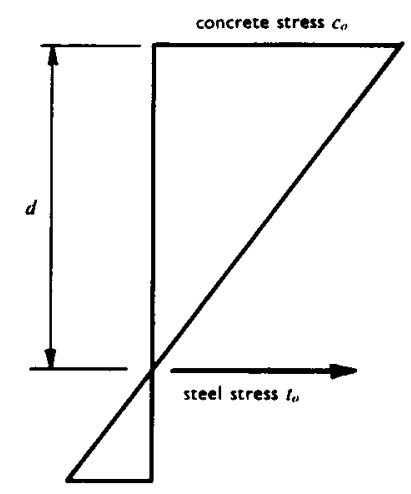

Figure $\mathrm{K}$
$100,000 \mathrm{lb} / \mathrm{in}^{2}$ on $t_{o}$, means that $c_{u} / p_{s}$ must be at least 6,000 . This is not unreasonable. If we adhere to these limits large areas of the upper half of Figure $J$ are excluded from practical consideration.

Figure L (a) shows $t_{o}=100,000$ and $160,000 \mathrm{lb} / \mathrm{in}^{2}$ and a curve representing the equation $t_{o}=16.6 c_{u} / p_{s}$. The latter is obtained from the intersections of the $c_{u} / p_{s}$ lines with the $t_{o}$ curves. Figure L (a) also plots the relationship $t_{o}=0.7 t_{u}$ which Dr Hajnal-Kónyi has suggested to avoid brittle failure. The curve $t_{o}=0$ is included only for comparison. With these limits the intersection points for $c_{u} / p_{s}$ lines and $t_{o}$ curves must be in the black area, unless the steel fractures. In this case the intersection points lie on the line $t_{u}=280,000 \mathrm{lb} / \mathrm{in}^{2}$. It can be seen that compression failures are confined to the range $0.15<n_{1}<$ 0.5 corresponding to $0.07<M / b d^{2} c_{u}<0.20$.

Figure $\mathbf{L}(\mathrm{a})$ is drawn for $F^{\prime} e^{\prime}{ }_{c}=0.002$. Figure $\mathrm{L}(\mathrm{b})$ shows the same limits drawn for $F^{\prime} e^{\prime}{ }_{c}=0 \cdot 016$. In this case we get steel fracture for $n_{1}$ as high as 0.58 , giving $M / b d^{2} c_{u}=0 \cdot 22$. Compression failures raise the limit to $M / b d^{2} c_{\mu}=0.26$. To achieve the $18 \%$ increase from 0.22 to $0.26 \mathrm{M} / b d^{2} c_{u}$ we must decrease $c_{u} / p_{s}$ from 10,000 to 6,000 , which for a given cube strength is a $67 \%$ increase in steel. The value $\mathbf{0 . 2 2}$ seems, therefore, to be the practical upper limit for $M / b d^{2} c_{u}$. This agrees with $M / b d^{2} c_{u}=$ 0.225 suggested as a suitable maximum in the First Report on Prestressed Concrete published by the Institution of Structural Engineers (1951). Mr Revesz has suggested $0 \cdot 20$.

As a safe approximation, the two black areas in Figures $L$ (a) and (b) can be replaced by lines $X-X$ and $Y-Y$ respectively. Similar approximations can be made for intermediate values of $F^{\prime} e^{\prime}{ }_{c}$. The separate diagrams can then be superimposed as in Figure M. This diagram is an approximate representation of Professor Baker's theory for pre-tensioned beams using 12 S.W.G. hightensile wire, with the stated limits on the prestress.

This diagram, simple though it is, does not surmount or dodge the basic difficulty of Professor Baker's theory. We still have this awkward variable $F^{\prime} e^{\prime} c$. This, I think, is the essence of Dr Hajnal-Konyi's complaint that the theory is difficult to apply. Professor Baker settles for $F^{\prime} e_{c}^{\prime}=0.002$. But in the case of Mr Revesz's beams, and the beams which Dr Hajnal-Kónyi tested, $F^{\prime} e^{\prime}{ }_{c}=0.002$ leads to a considerable underestimate of the strength.

$\mathrm{Mr}$ Revesz says that the theory is difficult to apply to pre-tensioned beams. He says further that up to a practical limit the strength of such beams is governed by a comparatively simple law. The limit is $M / b d^{2} c_{u}=0.22$. Mr Revesz's results follow a simple law up to this limit because his beams all failed in tension. Compression failures can occur below this limit, as my tests have shown. In these cases the law is not simple because equation (3) is applicable and a suitable value for $F^{\prime} e^{\prime} c$ must be selected.

Clearly more tests are needed to determine suitable values of $F^{\prime} e^{\prime}$ for pre-tensioned beams. Such tests should be carried out on full-scale beams. Beams of the size used 


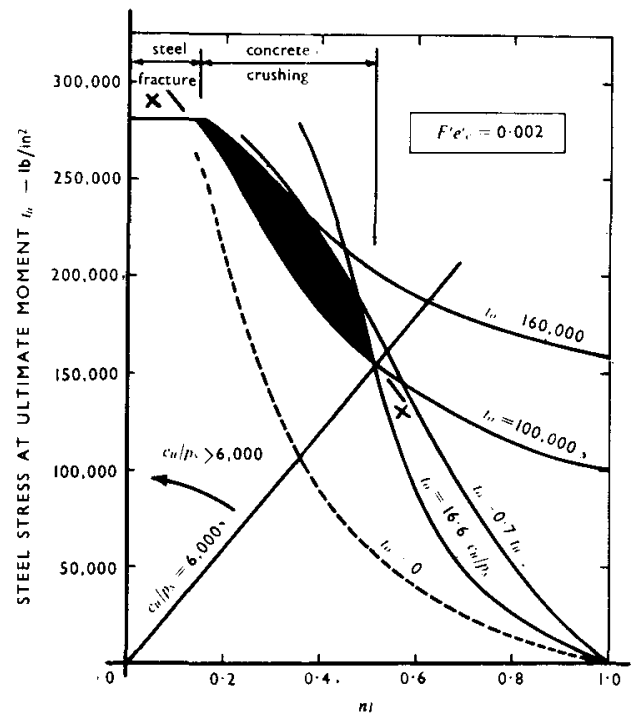

(a)

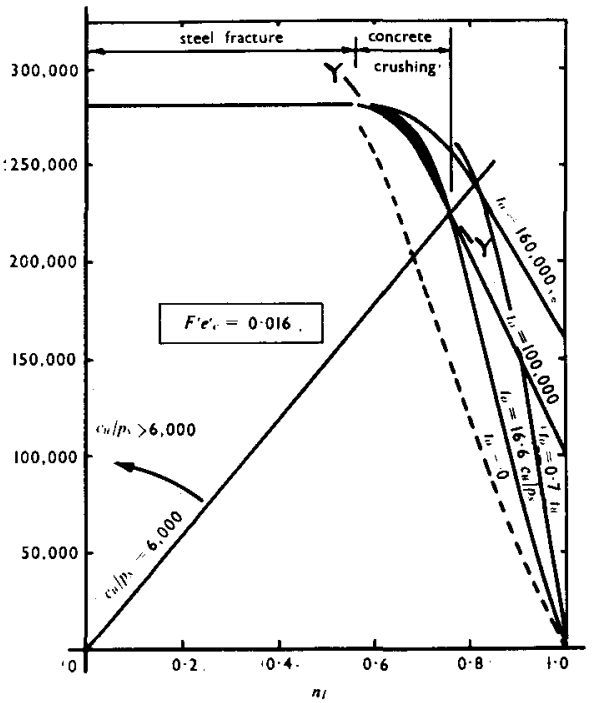

(b)

Figure L

by $\mathrm{Mr}$ Nisbet and myself are economical to test and can give useful information, but there are inherent difficulties, such as those of measuring the strains, and it is better that design factors be deduced from full-scale tests. Such tests may show that values of $F^{\prime} e_{c}^{\prime}$ of 0.016 or more can be realized consistently in pre-tensioned beams. In this event Mr Revesz's conclusions will be justified.

It seems unlikely, however, that such high values of $F^{\prime} e^{\prime}{ }_{c}$ are possible for grouted post-tensioned beams, and the problem of selecting a suitable value remains.

The quantity $F^{\prime}$ is obviously intimately connected with the flexural bond stresses studied by Janney, whose name has appeared so frequently in this discussion. With so much emphasis laid on bond phenomena it seems to me proper to close with the final paragraph of the paper by Hognestad and Janney. Having summarized their work they conclude:

"From this point on, we are confronted with the same problems in pre-tensioned prestressed concrete that are before us in conventional reinforced concrete. How are flexural bond stresses due to shear and those at cracks distributed? What is their relative importance when other reinforcement percentages than those we tested are used? To answer these questions, more must be learned about the cracking pattern of prestressed as well as of conventionally reinforced concrete and about the mechanism of bond action in the vicinity of cracks. Until such knowledge becomes available, it seems wise to approach the question of bond in pre-tensioned prestressed concrete with caution." (My italics.)

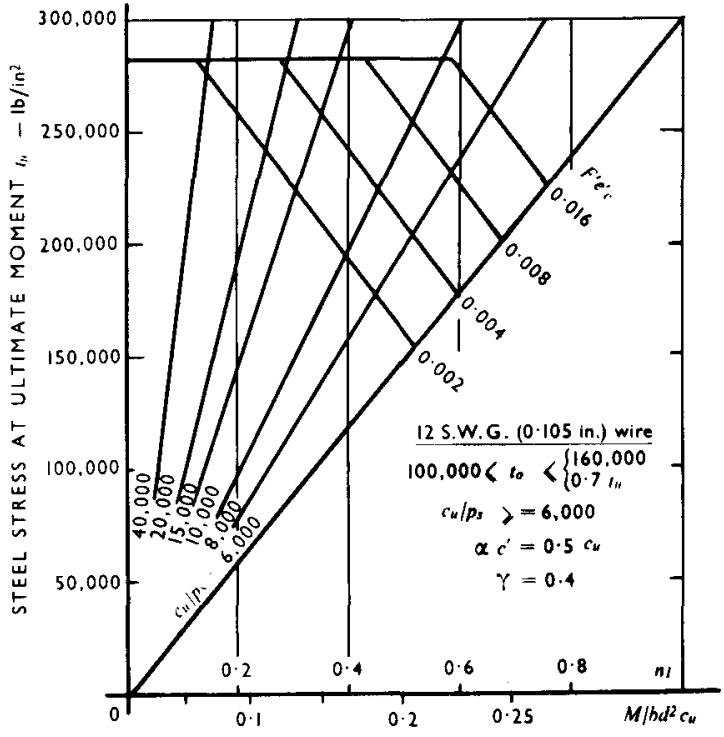

Figure $M$

\section{REFERENCE}

(1) HOGNESTAD, E. and JANNEY, J. R. The ultimate strength of pre-tensioned prestressed concrete failing in bond. Magazine of Concrete Research. Vol. 6, No. 16. June 1954. pp. 11-16. 